\title{
Participation of mast cells in chronic otitis media
}

\author{
Anna Pajor ${ }^{1}$, Marian Danilewicz ${ }^{2}$, Andrzej Jankowski ${ }^{1}$, Tomasz Durko ${ }^{1}$ \\ ${ }^{1}$ Department of Otolaryngology, Medical University of Lodz, Poland \\ ${ }^{2}$ Department of Nephropathology, Morphometry Division, Medical University of Lodz, Poland
}

\begin{abstract}
In the pathogenesis of chronic otitis media (COM), much attention is paid to the molecular mechanisms of local inflammatory reactions in which mast cells (MCs) may be involved due to their role not only in allergic but also inflammatory processes. The aim of this study was to assess the density of mast cells in chronic otitis media in relationship to different clinical courses of COM, bacterial infections and types of disease. The MCs expression was measured immunohistochemically in paraffin-embedded granulation tissue specimens taken during surgery, by staining with a monoclonal antibody against tryptase. The density of tryptase-positive mast cells was lower in tissue samples from the group with a good clinical course than in those from the group with poor healing and recurrence $(p=0.006)$. There were no differences between the groups of patients with granulomatous and cholesteatomatous chronic otitis media $(\mathrm{p}=0.66)$ or between the groups of patients with and without bacterial infection $(\mathrm{p}=0.30)$, although the density of mast cells was lower for those with Pseudomonas aeruginosa/Proteus sp./ /Staphyloccocus MRSA infection. In conclusion, the expression of mast cells in chronic otitis media granulation tissue was found to differ depending on the clinical course of the disease, but not on bacterial infection or type of COM. This may suggest that mast cells contribute to the maintenance of the inflammatory process, but not to antibacterial defense in chronic otitis media. (Folia Histochemica et Cytobiologica 2011; Vol. 49, No. 3, pp. 479-485)
\end{abstract}

Key words: chronic otitis media, granulation tissue, mast cells, tryptase

\section{Introduction}

Chronic otitis media (COM) is defined as permanent inflammatory disease in the middle ear and mastoid cavity with the presence of tympanic membrane perforation, discharge from the ear and often a proliferative process of the mucosal lining in the form of granulation tissue, polyp or cholesteatoma. It is one of the most important causes of acquired hearing loss. In recent years, more attention has been paid to molecular mechanisms of local inflammatory reactions in the pathogenesis of COM [1]. Typically, polymorphonuclear neutrophils, macrophages and their mediators take part in the chronic inflammatory process. Growing evidence points to the role of mast cells (MCs) not only in allergic but also in inflammatory

Correspondence address: A. Pajor, Department of

Otolaryngology, Medical University of Lodz,

Barlicki University Hospital,

Kopcinskiego Str. 22, 90-153 Lodz, Poland;

tel./fax: (+ 4842$) 6785785$;

e-mail: grappa@csk.umed.lodz.pl, anna.pajor@umed.lodz.pl reactions [2,3]. This possible function of mast cells is associated with their specific localization closely to the external environment, their long life, and a wide spectrum of mediators stored in the granules of MCs [4]. It has been postulated that they are involved in chronic inflammatory diseases such as asthma, rheumatoid arthritis, coronary disease, bullous pemphigoid, interstitial cystitis, chronic bowel and intestinal diseases and multiple sclerosis [5, 6].

Mastocytes participate in nonspecific immunological mechanisms in host defense against pathogens. They can phagocytize bacteria and release pro-inflammatory mediators due to contact with bacteria and their products [3, 4]. Mastocytes can also regulate the adaptive immunity to infection by modulation of dendritic cell and T-cell responses $[3,7,8]$ and contribute to tissue remodeling in chronic inflammation [9].

Mast cells are distributed abundantly in skin, lymphatic organs, mucosa of gastrointestinal and respiratory tracts. They are also present in middle ear mucosa in both animals and humans, especially in pars flaccida of tympanic membrane, in tubotympanum and pharyngeal ostium of Eustachian tube [10,11]. 
In the middle ear, the highest density of MCs has been reported in well vascularized mucosa or mucosa covered by ciliated epithelium [11]. MCs are more abundant in the epithelium than in the subepithelial layer, as compared to adenoid [12].

The role of mast cells and their mediators, such as tryptase and histamine, has been assessed in pathology of the middle ear mainly in adenoid hypertrophy and otitis media with effusion (OME) [13-17]. Some studies have found increased number of MCs and higher levels of histamine in adenoid, which may indicate that mast cells are the source of inflammatory mediators for Eustachian tube and middle ear [13-15]. Increased counts of MCs and elevated tryptase levels, in effusion and in middle ear mucosa, have been demonstrated in allergic patients with OME $[16,17]$. Clinical studies reporting high histamine levels in middle ear effusion in secretory otitis media $[12,18]$ and in acute otitis [19], as well as experimental studies of guinea pigs in which histamine injection into the tympanic cavity had caused long-standing effusion [20], also point to histamine participation in the pathomechanism of middle ear inflammation.

Mast cells have rarely been investigated in chronic otitis media and only a few studies about their participation in cholesteatoma are accessible. There are none dealing with the clinical features in COM. Albino et al. [21] found a 3- to 7-fold increased number of MCs in different types of cholesteatoma, more intense in a primary acquired one, and their localization was typical for intensive inflammatory process. The presence of tryptase and chymase has been reported in middle ear cholesteatoma, pointing to a participation of MCs proteases in the pathogenesis of the disease [22]. Sankovic et al. [23] found MCs in nearly all middle ear biopsies, although they were degranulated to a lesser extent in COM $(37.8 \%)$ than in OME $(81.8 \%)$.

Therefore, investigating the possible influence of mast cells on the outcome of COM, as an example of chronic inflammation, seems important. This is why the aim of our study was to assess the density of mast cells in granulation tissue in chronic otitis media and evaluate their participation in postoperative healing and recurrence of the disease, in concomitant bacterial infection, and in a type of COM.

\section{Material and methods}

Characteristics of study groups. Fifty-four patients (33 men, 21 women) with chronic otitis media, who had undergone surgical treatment, were enrolled into the study. The mean age was $46.4 \pm 15.6$ years, ranging from 19 to 77 years. All patients were assessed prior to surgery and operated on by the same surgeon (T.D.). Twenty one patients were subjected to radical mastoidectomy and 33 patients to radical modified mastoidectomy. Both operations are open (canal wall down) approaches, so the posterior canal wall between the tympanic cavity and the mastoid process is removed to improve drainage and aeration of middle ear cavities. The radical mastoidectomy is an extended type of operation in which all damaged tympano-ossicular elements (tympanic membrane, malleus, incus) are removed, in contrast to radical modified mastoidectomy, in which those which are still working are preserved during surgery and may serve for tympanoplasty [24]. The degrees of COM severity were nearly similar in this sample since the patients were subjected to types of operation, which are based on the same surgical strategy intended to avoid recurrence. Both of these operations are used in more advanced stage of COM.

The study group was divided according to clinical course of disease as follows:

- group NR (no recurrence) - consisted of 25 patients (mean age $50.8 \pm 17.8$ years, 11 women) with a good clinical course, ear cavity healed well postoperatively and epithelialised after three months, there was no long-term discharge or recurrence of inflammation during five-year follow-up;

- group R (recurrence) - consisted of 29 patients (mean age $42.7 \pm 12.6$ years, ten women) with poor postoperative healing and recurrence of disease during five-year follow-up.

The patients were divided also according to coexistence and type of bacterial infection into three groups:

- group B0 ( $\mathrm{n}=14$ patients $)$ - with no concomitant bacterial infection;

- group B1 ( $\mathrm{n}=20$ patients $)$ - with Pseudomonas aeruginosa/Proteus sp./Staphyloccocus MRSA infection which constitute a separate group, as these bacteria are typical for COM but very difficult to eradicate. In group B1, Pseudomonas aeruginosa was the most frequent pathogen (17 patients, in one case coexistent with Staphylococcus aureus), Proteus sp. was noted in two patients and Staphylococcus aureus MRSA in one patient;

- group B2 ( $\mathrm{n}=20$ patients $)$ — with bacterial infection different to that in group B1. In group B2, the following bacteria were found: Dyphteroides sp. - five patients (coexistent with Escherichia coliESBL (-) - two patients), Staphylococcus epidermidis - four patients, Staphylococcus aureus - ten patients (coexistent with Streptococcus pneumoniae - one patient) and Escherichia coli ESBL (-) - one patient. Fungal infection by Candida parapsilosis was observed as concomitant with a bacterial one, in one case with Staphylococcus aureus, and in one case - with Pseudomonas aeruginosa and Staphylococcus aureus.

The study group was divided according to type of COM into:

- group G - granulomatous type, without cholesteatoma ( $n=38$ patients, mean age $46.8 \pm 15.6$ years, 16 women $)$;

- and group $\mathrm{CH}$ - cholestatomatous type ( $\mathrm{n}=16$ patients, mean age $45.6 \pm 16.0$ years, five women). 
Group R was younger than group NR (42.7 vs. 50.8 years respectively, $\mathrm{p}=0.057$ ) and Pseudomonas aeruginosa/Proteus sp./Staphyloccocus MRSA infection was more frequently found in this group (55.2\% vs. $16 \%$ respectively, $\mathrm{p}=0.002)$.

Moreover, bacterial infection (both from B1 and B2 groups) was observed more often in the cholesteatoma group than in the granulomatous group (93.8\% vs. $65.8 \%$ respectively, $\mathrm{p}=0.003$ ). The recurrence of COM was mostly observed in the B1 group followed by the B0 and then the B2 ( $80 \%$ vs. $42.9 \%$ vs. $35 \%$, respectively, $\mathrm{p}=0.003)$. Nearly the same percentage of good and poorer clinical course was observed in both types of COM (no recurrence in $\mathrm{G}$ and CH groups: $47.4 \%$ vs. $43.7 \%$, respectively).

The Bioethics Committee of the Medical University of Lodz approved the study protocol (Document No. RNN/ /57/09/KE).

Tissue samples. The density of mast cells was evaluated immunohistochemically by assessing tryptase activity in granulation samples removed during surgery from the tympanic cavity. Sections were prepared from formalin-fixed, paraffin-embedded material. In all specimens, the presence of granulation tissue was confirmed by a histopathologist (M.D.). In the pilot study, we identified mast cells in granulation tissue with toluidine blue staining and about half of them were degranulated.

Moreover, in all patients, the bacteriological examination to aerobes and fungi was made. The smears were obtained using sterile cotton swabs, then placed on agar plates for incubation, and identified. The tests determining phenotypes and mechanisms of resistance of isolated pathogens were also performed (MRSA, ESBL, HLAR, MLSB, MBL, VISA/VRSA).

Immunohistochemistry (IHC). For immunohistochemical assay, $4 \mu \mathrm{m}$ paraffin sections were mounted onto superfrost slides, deparaffinated in a sequence of xylene, dehydrated in a series of alcohols and rinsed twice in distilled water. Antigen was treated with $0.01 \mathrm{M}$ citrate buffer, $\mathrm{pH} 6.0$ (DAKO, Target Retrieval Solution) by heating in a microwave oven (parameters: $360 \mathrm{~W}-2 \times 3$ minutes, $180 \mathrm{~W}-$ $2 \times 5$ minutes and $90 \mathrm{~W}-2 \times 5$ minutes). After cooling, sections were rinsed twice in $0.05 \mathrm{M}$ buffer TRIS (TBS, DAKO), pH 7.6 for 5 minutes and incubated with $3 \%$ hydrogen peroxide $\left(\mathrm{H}_{2} \mathrm{O}_{2}\right)$ for 10 minutes in order to block endogenous peroxidase activity. Then monoclonal mouse anti-human Mast Cell Tryptase (Clone AA1, Dako Cytomation, Glostrup, Denmark, dilution 1:100) was applied. The sections were incubated for 1 hour with primary antibody diluted with DAKO Antibody Diluent with Background Reducing Components in a humid chamber at room temperature. Afterwards, sections were rinsed twice in TBS and visualisation system EnVision/HRP/DAB+ (DAKO Cytomation, Glostrup, Denmark) was used according to the manufacturer's instruction. After 30 minutes' incubation with horseradish peroxidase-conjugated secondary antibodies, the positive immunoreactivity was visualised using 3,3'-diaminobenzidine tetrachloride (DAB) as chromogen. After washing in distilled water, sections were counter-stained with hematoxylin and coverslipped. Negative controls were carried out by incubation in the absence of the primary antibody, and always yielded negative results.

Morphometry. Staining of tryptase-positive mast cells was evaluated using a computer image analysis system consisting of a PC equipped with a Pentagram graphic tablet, an Indeo Fast card (frame grabber, true-color, real-time) produced by Indeo (Taiwan), and a color TV camera produced by Panasonic (Japan) coupled with a Carl Zeiss microscope (Germany). This system was programmed (MultiScan 8.08 software, produced by Computer Scanning Systems, Poland) to calculate the number of objects (automatic or semi-automatic function).

The density of tryptase-positive mast cells was evaluated using automatic function of MultiScan, with manual correction as needed. The $8-10$ monitor fields $\left(0.029 \mathrm{~mm}^{2}\right.$ each $)$ were analyzed according to the size of the section. The results were expressed as the mean number of tryptase-positive mast cells per $\mathrm{mm}^{2}$ of the section. The example of tryptasepositive mast cells expression is presented in Figure 1.

Data analysis and statistics. Statistical analysis was performed by Statistica version 6.0 software. Data was expressed as means \pm standard deviation (SD). Data was checked for normality by the Shapiro-Wilk test and for the homogeneity of variance by Levene's test. The Mann-Whitney U test and one-way analysis of variance (ANOVA) were applied for comparison of groups. A two-way repeated-measures

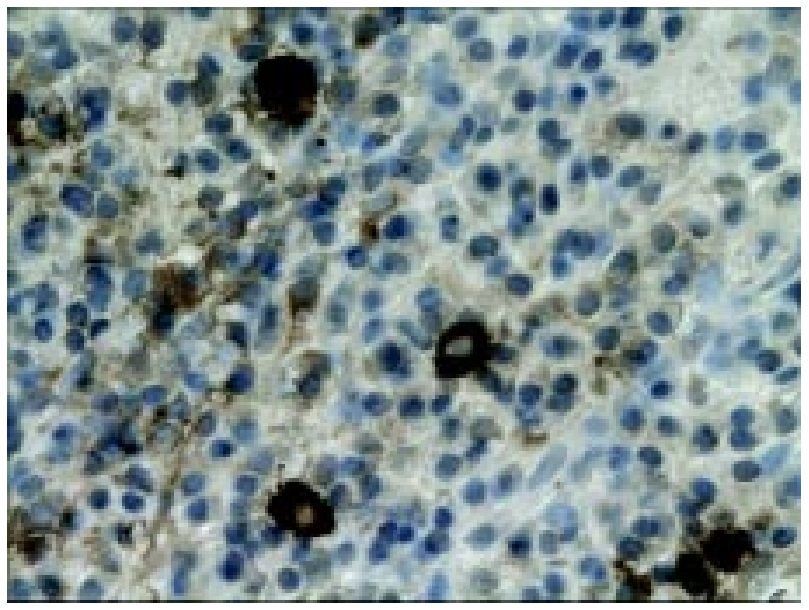

Figure 1. Tryptase-positive mast cells in granulation tissue in patient with poor clinical course of chronic otitis media. Immunostaining with anti-tryptase monoclonal antibody, magnification $\times 400$ 
Table 1. Mean values of tryptase-positive mast cells density in granulation tissue in different groups of patients with chronic otitis media $(\mathrm{n}=54)$

\begin{tabular}{|c|c|c|c|}
\hline Mast cells (number/mm²) & Range (min-max) & Mean \pm SD & $\mathrm{p}$ \\
\hline Whole group $(\mathrm{n}=54)$ & $2.0-137.2$ & $102.1 \pm 25.7$ & \\
\hline $\begin{array}{l}\text { Group NR }(\mathrm{n}=25) \\
\text { Group R }(\mathrm{n}=29)\end{array}$ & $\begin{array}{c}46.1-134.7 \\
2.0-137.2\end{array}$ & $\begin{array}{c}94.9 \pm 24.1 \\
108.3 \pm 25.8\end{array}$ & 0.006 \\
\hline $\begin{array}{l}\text { Group B0 }(n=14) \\
\text { Group B1 }(n=20) \\
\text { Group B2 }(n=20)\end{array}$ & $\begin{array}{c}68.2-137.2 \\
2.0-132.9 \\
72.1-136.3\end{array}$ & $\begin{array}{c}109.2 \pm 22.4 \\
95.6 \pm 30.1 \\
103.7 \pm 22.5\end{array}$ & 0.30 \\
\hline $\begin{array}{l}\text { Group G }(\mathrm{n}=38) \\
\text { Group CH }(\mathrm{n}=16)\end{array}$ & $\begin{array}{c}46.1-137.2 \\
2.0-132.9\end{array}$ & $\begin{array}{c}103.8 \pm 22.5 \\
98.2 \pm 32.6\end{array}$ & 0.66 \\
\hline
\end{tabular}

Group N - good clinical course of chronic otitis media (COM); group R - recurrence of COM; group B0 — without bacterial infection; group B1 - with Pseudomonas aeruginosa/Proteus sp./Staphyloccocus MRSA infection; group B2 - with bacterial infection different to that of group $\mathrm{B} 1$; group $\mathrm{G}$ - granulomatous $\mathrm{COM}$; group $\mathrm{CH}$ - cholestatomatous $\mathrm{COM}$

ANOVA with post-hoc LSD Fisher test, if appropriate, were carried out on the density of mast cells for the following factors: clinical course of COM (no recurrence-recurrence), presence and type of bacterial infection, type of COM (granulomatous - cholesteatomatous). The differences were considered statistically significant when $\mathrm{p}$ was less than 0.05 .

\section{Results}

In the whole group with chronic otitis media, the mean density of tryptase-positive mast cells was 102.1 and ranged from 2.0 to 137.2 per $\mathrm{mm}^{2}$ of the section. The mean value of tryptase-positive MCs was significantly lower in the COM group with a good clinical course compared to the group with recurrence of disease (94.9 vs. 108.3 respectively, $p=0.006$ ) (Table 1$)$. There were no significant differences in the mean density of tryptase-positive MCs between groups with and without concomitant bacterial infection (one-way ANOVA p $=0.30$ ); however, the Pseudomonas aeruginosa/ /Proteus sp/Staphyloccocus MRSA group had lower values than the $\mathrm{B} 0$ and $\mathrm{B} 2$ groups (95.6 vs. 109.2 vs. 103.7 respectively; post hoc tests: groups $\mathrm{B} 0-\mathrm{B} 1: \mathrm{p}=$ $=0.13, \mathrm{~B} 0-\mathrm{B} 2: \mathrm{p}=0.54, \mathrm{~B} 1-\mathrm{B} 2: \mathrm{p}=0.32)$. Similar$\mathrm{ly}$, there were no significant differences between the granulomatous and cholesteatomatous types of COM $(\mathrm{p}=0.66)$.

The results of two-way ANOVA revealed that there was a significant main effect only for clinical course of COM (F = 7.97; df = 1; p = 0.007) and a tendency to main effect on presence and type of bacterial infection $(\mathrm{F}=3.04 ; \mathrm{df}=2 ; \mathrm{p}=0.057)$, but the interaction effect between these factors was not significant $(\mathrm{p}=0.98)$ (Figure 2). The two-way ANOVA showed no interaction between clinical course and type of COM $(p=0.28)$ or between type of COM and bacterial infection $(\mathrm{p}=0.36)$.

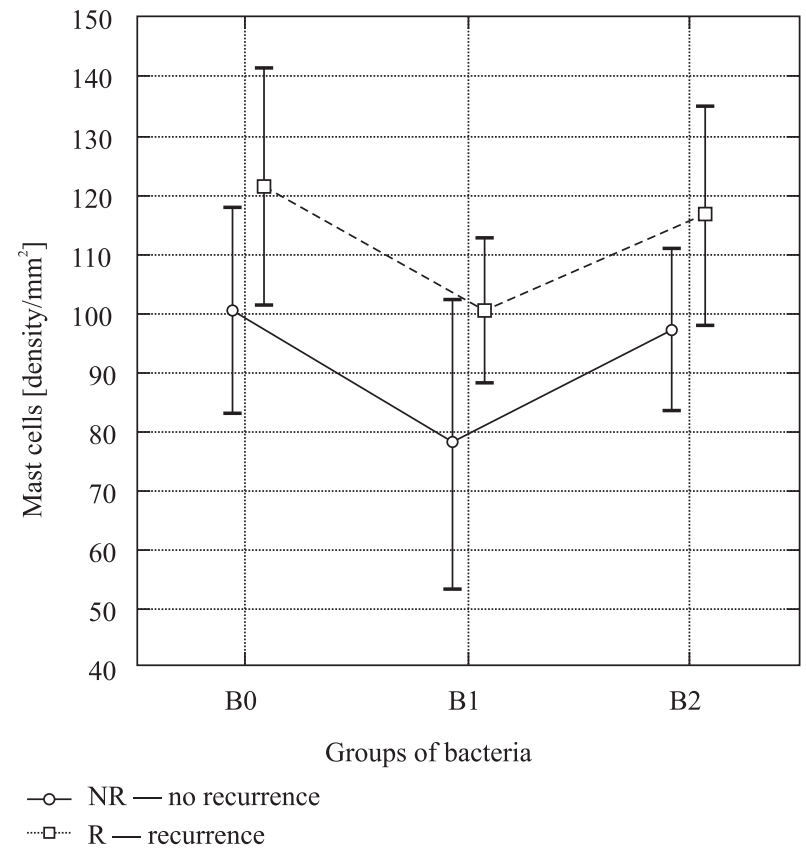

Figure 2. Tryptase-positive mast cell density (mean \pm SEM) in groups compared by clinical course of chronic otitis media and bacterial infection; SEM - standard error of mean

\section{Discussion}

Our study assessed the participation of mast cells in chronic otitis media in relationship to some clinical features of the disease such as course, concomitant bacterial infection and type of COM. We used one of the human MCs' serine proteases, i.e. tryptase, which occurs in several types, including $\beta$-tryptase which is the main type stored in MCs' secretory granules. Tryptase occurs almost exclusively in mast cells and in trace amounts in basophiles, so it is considered as a reliable marker of MCs' activation [25]. 
Our study found that patients with poorer postoperative healing and recurrence had significantly higher density of tryptase-positive mast cells than those with a good clinical course of chronic otitis media. This may suggest that mastocytes contribute to the maintenance of the inflammatory process. The role of mast cells in chronic inflammation is not fully understood. It has been reported that they are increased in inflammatory processes but there is contradictory evidence of their effect i.e. protective or deleterious [6]. This dual role of MCs in modulating inflammatory responses is realized by different mechanisms [26]. They release a wide range of mediators, such as preformed mediators, de novo synthesized mediators and cytokines, which can regulate inflammation [27]. Mastocytes are implicated in the recruitment and activation of neutrophils, monocytes/macrophages, and other inflammatory cells to sites of infection $[6,28]$, in directing effector $\mathrm{T}$ cells and dendritic cells $[29,30]$ and in interplay with regulatory T cells [31]. They act also as epithelial and fibroblast mitogen in inflammatory tissue remodeling $[32,33]$ and in angiogenesis due to releasing heparin, histamine and angiogenic cytokines [5]. In middle ear structures, it has been shown that mast cells' degranulation causes the inflammatory reaction of tympanic membrane [34]; however they may also contribute to healing of tympanic membrane perforations in acute otitis media [35]. It has also been demonstrated on the animal model of middle ear otitis that early inflammatory reaction to Haemophilus influenzae was less pronounced in $\mathrm{W} / \mathrm{Wv}$ mice which did not exhibit proto-oncogene c-kit expression, so did not have mast cells, than in wild-type mice and $\mathrm{W} / \mathrm{Wv}$ mice after reconstitution of MCs [36].

Bacterial infection often causes an exacerbation in the clinical course and failure in treatment in chronic otitis media. This was seen in our study in the group with Pseudomonas aeruginosa/Proteus sp./Staphyloccocus MRSA in which recurrence was twice as frequent as in other groups. Bacterial toxins may activate $\mathrm{MCs}$ which, in response to infection, release many mediators causing an increase in vascular permeability and in the expression of adhesion molecules or act chemotactically directly on neutrophils and eosinophils, and also produce anti-microbial peptides like cathelicidins and defensins. Activation of human mast cells has been demonstrated for Staphylococcus aureus and Pseudomonas aeruginosa, which are the most common isolates from chronic otitis media [37-40]. Chonmaitree et al. [19] reported that histamine levels were higher in bacteria-positive than bacteria-negative effusions in acute otitis media. Our study, however, failed to show any significant differ- ence in density of MCs in relationship to bacterial infection or to demonstrate its protective antibacterial role in the chronic inflammatory process. Interestingly, the lowest mean density of mast cells both in $\mathrm{N}$ and $\mathrm{R}$ groups was observed in an infection that was more difficult to eradicate (Pseudomonas aeruginosa/ /Proteus sp./Staphyloccocus MRSA). It is plausible that the persistent inflammation caused by more resistant bacteria has exhausted MCs' proinflammatory abilities. The possible mechanisms observed in Pseudomonas aeruginosa infection may be due to mast cell apoptosis induced by exotoxin A [41] or modulation of MCs' activity and the release of cytokines by quorum sensing in biofilms [42], which have also been shown in cholesteatoma [43].

In the current study, we have hypothesized that mast cells are likely to show higher activity in cholesteatoma which is considered as a more aggressive type of COM because of the frequent destruction of adjacent bone and soft tissues. Berger et al. [44] have postulated that mast cells may play a role in bone resorption in COM as they were increased in tissues close to eroded ossicles. MCs may also release mediators like TNF- $\alpha$, IL- $\beta$ or $N$-acetylo- $\beta$-D-hexosoaminidase known to participate in bone destruction in cholesteatoma [45, 46]. However, in our study, the fact that there was no difference in the mean density of mast cells between both types of COM suggests that they did not contribute more to cholesteatoma. Although our immunohistochemical examination was performed in granulation tissue close to cholesteatoma and not in its perimatrix, it seems that participation of mast cells in otitis media is related to the chronicity of inflammatory process, rather than its type.

\section{Conclusions}

The results of our study show that density of tryptasepositive mast cells in granulation tissue in chronic otitis media differs depending on clinical course, but not on bacterial infection or type of disease. It may suggest that mast cells contribute to the maintenance of inflammatory process, but not to antibacterial defense in chronic otitis media.

\section{Acknowledgements}

The work was supported by Medical University of Lodz, grant no. 503-2036-1.

\section{References}

1. Juhn SK, Jung M-K, Hoffman MD et al. The role of inflammatory mediators in the pathogenesis of otitis media and sequelae. Clin Exper Otorhinolaryngol. 2008;1:117-138. 
2. Mekori YA. The mastocyte: the "other" inflammatory cell in immunopathogenesis. J Allergy Clin Immunol. 2004;114: 52-57.

3. Dawicki W, Marshall JS. New and emerging roles for mast cells in host defence. Curr Opin Immunol. 2007;19:31-38.

4. Féger F, Varadaradjalou S, Gao Z, Abraham SN, Arock M. The role of mast cells in host defense and their subversion by bacterial pathogens. Trends Immunol. 2002;23:151-158.

5. Crivellato E, Ribatti D. Involvement of mast cells in angiogenesis and chronic inflammation. Current Drug Targets Inflammation \& Allergy. 2005;4:9-11.

6. Metz M, Grimbaldeston MA, Nakae S, Piliponsky AM, Tsai M, Galli A. Mast cell in promotion and limitation of chronic inflammation. Immunol Rev. 2007;217:304-328.

7. Galli SJ, Nakae S, Tsai M. Mast cells in the development of adaptive immunological response. Nat Immunol. 2005:6: 135-142.

8. Shelburne CP, Nakano H, St John AL et al. Mast cells augment adaptive immunity by orchestrating dendritic cell trafficking through infected tissues. Cell Host Microbe. 2009; 6:331-342.

9. Caughey GH. Mast cell tryptases and chymases in inflammation and host defense. Immunol Rev. 2007;217:141-154.

10. Widemar L, Hellström S, Stenfors L-E, Bloom GD. An overlooked site of tissue mast cells - the human tympanic membrane. Implications for middle ear affections. Acta Otolaryngol (Stockh). 1986;102:391-395.

11. Watanabe T, Kawauchi H, Fujiyoshi T, Mogi G. Distribution of mast cells in the tubotympanum of guinea pigs. Ann Otol Rhinol Laryngol. 1991;100:407-412.

12. Palva T, Taskinen E, Lehtinen T, Ramsay H, Björksten F, Hackman P. Mast cells and histamine in adenoid tissue and middle ear. Acta Otolaryngol (Stockh). 1991;111:349-353.

13. Ulualp SO, Sahin D, Yilmaz N, Anadol V, Peker O, Gursan O. Increased adenoid mast cells in patients with otitis media with effusion. Int J Pediatr Otorhinolaryngol. 1999;49:107-114.

14. Abdullah B, Hassan S, Sidek D, Jaafar H. Adenoid mast cells and their role in the pathogenesis of otitis media with effusion. J Laryngol Otol. 2006;120:556-560.

15. Collins MP, Church MK, Bakhski KN, Osborne J. Adenoid histamine and its possible relationship to secretory otitis media. J Laryngol Otol. 1985;99:685-691.

16. Hurst DS, Amin K, Seveus L, Venge P. Evidence of mast cell activity in the middle ears of children with otitis media with effusion. Laryngoscope. 1999;109:471-477.

17. Jang CH, Jung JK. Expression of mast cell tryptase in pediatric otitis media with effusion. Int J Pediatr Otorhinolaryngol. 2003;67:1185-1188

18. Berger G, Hawke M, Proops D, Ranadive NS, Wong D. Histamine levels in middle ear effusions. Acta Otolaryngol (Stockh). 1984;98:385-390.

19. Chonmaitree T, Patel JA, Lett-Brown MA et al. Virus and bacteria enhance histamine production in middle ear fluids of children with acute otitis media. J Infect Dis. 1994;169: 1265-1270.

20. Boisvert P, Wasserman SI, Schiff M, Ryan AF. Histamineinduced middle ear effusion and mucosal histopathology in the guinea pig. Ann Otol Rhinol Laryngol. 1985;94:212-216.

21. Albino AP, Reed JA, Bogdany JK, Sassoon J, Parisier SC. Increased numbers of mast cells in human middle ear cholesteatomas: implications for treatment. Am J Otol. 1998; 19:266-272.

22. Hochstrasser K, Albrecht GJ, Gebhard W, Rasp G, Kastenbauer E. Isolation and characterization of trypsin-like and chymotrypsin-like proteinases from human cholesteatoma. Eur Arch Otorhinolaryngol. 1994; 251:30-35.

23. Sankovic S, Degenc R, Bojic P. Mast cells in chronic inflammation of the middle ear mucosa. Rev Laryngol Otol Rhinol (Bord). 2005;126:15-18.

24. Telian SA, Schmalbach CE. Chronic otitis media. In: Snow JB, Ballenger JJ eds. Ballenger's Otorhinolaryngology Head Neck Surgery. Hamilton, Ontario: BC Decker; $16^{\text {th }}$ ed., 2003; 261-293.

25. Hallgren J, Pejler G. Biology of mast cell tryptase - an inflammatory mediator. FEBS J. 2006;273:1871-1895.

26. Kinet J-P. The essential role of mast cells in orchestrating inflammation. Immunol Rev. 2007;217:5-7.

27. Theoharides TC, Kempuray D, Tagen M, Conti P, Kalogeromitros D. Differential release of mast cells mediators and the pathogenesis of inflammation. Immunol Rev. 2007;217: $65-78$.

28. Malaviya R, Ikeda T, Ross E, Abraham SN. Mast cell modulation of neutrophil influx and bacterial clearance at sites of infection through TNF-alpha. Nature. 1996;381:77-80.

29. Mekori YA, Metcalfe DD. Mast cell-T cell interactions. J Allergy Clin Immunol. 1999;104:517-523.

30. Suto H, Nakae S, Kakurai M, Sedgwick JD, Tsai M, Galli SJ. Mast cell-associated TNF promotes dendritic cell migration. J Immunol. 2006;176:4102-4112.

31. Frossi B, Gri G, Tripodo C, Pucillo C. Exploring a regulatory role for mast cells: MCregs'. Trends Immunol. 2010; 31:97-102.

32. Cairns JA, Walls AF. Mast cell tryptase is a mitogen for epithelial cells. Stimulation of IL-8 production and intercellular adhesion molecule-1 expression. J Immunol. 1996;156: 275-283.

33. Sommerhoff CP. Mast cell tryptases and airway remodeling. Am J Respir Crit Care Med. 2001;164:S52-S58.

34. Eriksson PO, Hellström S. Degranulation of mast cells provokes a massive inflammatory reaction in the tympanic membrane. Laryngoscope. 2001;111:1264-1270.

35. Cayé-Thomasen P, Tos M. Mast cell clusters in pars tensa membranae tympani in acute otitis media: a possible role in perforation healing. Acta Otolaryngol (Stockh). 1996;116: 845-849.

36. Ebmeyer J, Furukawa M, Pak K et al. Role of mast cells in otitis media. J Allergy Clin Immunol. 2005;116:1129-1135.

37. Arock M, Ross E, Lai-Kuen R, Averlant G, Gao Z, Abraham SN. Phagocytic and Tumor Necrosis Factor alpha response of human mast cells following exposure to Gram-negative and Gram-positive bacteria. Infect Immun. 1998;66: 6030-6034.

38. Rocha-de-Souza CM, Berent-Maoz B, Mankuta D, Moses AE, Levi-Schaffer F. Human mast cell activation by Staphylococcus aureus: interleukin- 8 and tumor necrosis factor alpha release and the role of Toll-like receptor 2 and CD48 molecules. Infect Immun. 2008;76:4489-4497.

39. Lin TJ, Garduno R, Boudreau RT, Issekutz AC. Pseudomonas aeruginosa activates human mast cells to induce neutrophil transendothelial migration via mast cell-derived IL-1 alpha and beta. $J$ Immunol. 2002;169:4522-4530.

40. Boudreau RTM, Garduno R, Lin T-J. Protein phosphatase $\mathrm{A} 2$ and protein kinase $\mathrm{Ca}$ are physically associated and are involved in Pseudomonas aeruginosa-induced interleukin 6 production by mast cells. J Biol Chem. 2002:277:5322-5329 .

41. Jenkins CE, Swiatoniowski A, Issekutz AC, Lin TJ. Pseudomonas aeruginosa exotoxin $\mathrm{A}$ induces human mast 
cell apoptosis by a caspase- 8 and -3-dependent mechanism. J Biol Chem. 2004;279:37201-37207.

42. Li H, Wang L, Ye L et al. Influence of Pseudomonas aeruginosa quorum sensing signal molecule $\mathrm{N}$-(3-oxododecanoyl) homoserine lactone on mast cells. Med Microbiol Immunol. 2009;198:113-121.

43. Chole RA, Faddis BT. Evidence for microbial biofilms in cholesteatomas. Arch Otolaryngol Head Neck Surg. 2002; 128: $1129-1133$.
44. Berger G, Hawke M, Ekem JK. Bone resorption in chronic otitis media. The role of mast cells. Acta Otolaryngol (Stockh). 1985;100:72-80.

45. Vitale RF, Ribeiro F deAQ. The role of Tumor Necrosis Factor-Alpha (TNF- $\alpha$ ) in bone resorption present in middle ear cholesteatoma. Rev Bras Otorrinolaringol. 2007; 73:123-127.

46. Olszewska E, Olszewski S, Borzym-Kluczyk M, Zwierz K. Role of N-acetyl-b-D-hexosaminidase in cholesteatoma tissue. Acta Biochim Pol. 2007;54:365-370.

Submitted: 1 July, 2010

Accepted after reviews: 30 January, 2011 